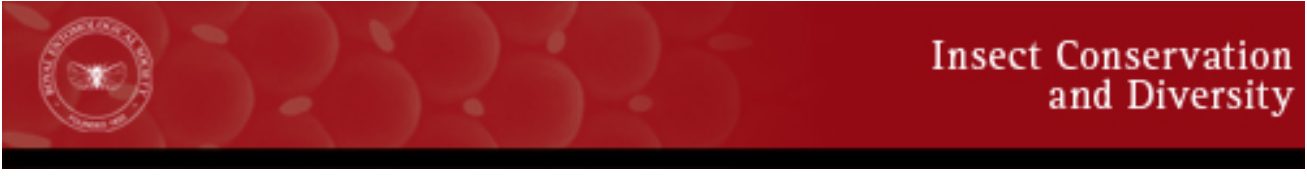

\title{
The role of climate and biotic factors in shaping current distributions and potential future shifts of European Neocrepidodera (Coleoptera, Chrysomelidae)
}

\begin{tabular}{|c|c|}
\hline Journal: & Insect Conservation and Diversity \\
\hline Manuscript ID & ICDIV-19-0099.R1 \\
\hline Manuscript Type: & Original Article \\
\hline $\begin{array}{r}\text { Date Submitted by the } \\
\text { Author: }\end{array}$ & $\mathrm{n} / \mathrm{a}$ \\
\hline Complete List of Authors: & $\begin{array}{l}\text { Cerasoli, Francesco; Universita degli Studi dell'Aquila Dipartimento di } \\
\text { Medicina Clinica Sanita Pubblica Scienze della Vita e dell'Ambiente, } \\
\text { MeSVA - Environmental Sciences } \\
\text { Thuiller, Wilfried; Universite Grenoble Alpes; Centre National de la } \\
\text { Recherche Scientifique; Universite Savoie Mont-Blanc; Laboratoire } \\
\text { d'Ecologie Alpine } \\
\text { Gueguen, Maya; Universite Grenoble Alpes; Centre National de la } \\
\text { Recherche Scientifique; Universite Savoie Mont-Blanc; Laboratoire } \\
\text { d'Ecologie Alpine } \\
\text { Renaud, Julien; Universite Grenoble Alpes; Centre National de la } \\
\text { Recherche Scientifique; Universite Savoie Mont-Blanc; Laboratoire } \\
\text { d'Ecologie Alpine } \\
\text { D'Alessandro, Paola; Università degli Studi dell'Aquila Dipartimento di } \\
\text { Medicina Clinica Sanità Pubblica Scienze della Vita e dell'Ambiente } \\
\text { Biondi, Maurizio; Universita degli Studi dell'Aquila Dipartimento di } \\
\text { Medicina Clinica Sanita Pubblica Scienze della Vita e dell'Ambiente, } \\
\text { MeSVA - Environmental Sciences }\end{array}$ \\
\hline Keywords: & $\begin{array}{l}\text { Habitat Suitability Models, Flea Beetles, }<i>\text { Neocrepidodera }</ i>\text {, Climate } \\
\text { Change, Ensemble Modelling, Host Plants }\end{array}$ \\
\hline
\end{tabular}




\section{The role of climate and biotic factors in shaping current distributions and potential future shifts of European Neocrepidodera (Coleoptera, Chrysomelidae)}

Running title: Drivers of Neocrepidodera distributions

Cerasoli, F. ${ }^{*}$, Thuiller, W. ${ }^{2}$, Guéguen, M. ${ }^{2}$, Renaud, J. ${ }^{2}$, D’Alessandro, P. ${ }^{1}$, Biondi, M. ${ }^{1}$

${ }^{1}$ Department of Life, Health \& Environmental Sciences, Univ. of L'Aquila, L'Aquila, Italy

${ }^{2}$ Univ. Grenoble Alpes, CNRS, Univ. Savoie MontBlanc, Laboratoire d'Ecologie Alpine (LECA), Grenoble, France

* Correspondence: Francesco Cerasoli, Department of Life, Health \& Environmental Sciences, University of L'Aquila, Via Vetoio snc Coppito, 67100 L'Aquila, Italy

E-mail: francesco.cerasoli@univaq.it / francesco.cer91@gmail.com

\section{ABSTRACT}

1. The Western Paleartic species of Neocrepidodera Heikertinger (Coleoptera: Chrysomelidae: Galerucinae: Alticini) mostly occur in medium and high elevation ecosystems particularly sensitive to climate change.

2. Here, using ensemble projections from state-of-the-art habitat suitability modelling techniques, we investigated how climate change and associated changes in host availability may affect the persistence of three pairs of closely related Neocrepidodera taxa.

3. Modelled niches and suitability patterns reflected the current distributions of the targeted taxa. Neocrepidodera ligurica occupies a small portion of the broader environmental niche of $N$. melanostoma, and its narrow geographical range makes this species particularly vulnerable to potential loss of suitable habitats in Western Alps. Neocrepidodera cyanescens cyanescens and $N$. cyanescens concolor were found to occupy separate niches, but the non-significance of the niche similarity test suggested their divergence being probably due to allopatric processes. Neocrepidodera corpulenta and $N$. rhaetica showed partially overlapping niches, coherently with their co-occurrence in Western Alps. Most of the targeted taxa were predicted to potentially lose large portions of currently suitable areas in the forthcoming decades. 
4. Notwithstanding the candidate host plants did not emerge as most important predictors, except Aconitum lycoctonum for $N$. cyanescens concolor, a clear reduction of potential insect-plant cooccurrence areas resulted for most future scenarios.

5. Climate was confirmed to noticeably affect the distribution of the targeted taxa, among which $N$. ligurica, N. cyanescens concolor, $N$. corpulenta and $N$. rhaetica may need specific prioritization measures in the future decades, claiming for further attention on mountainous entomofauna in a warming world.

Keywords: Habitat Suitability Models, Flea Beetles, Neocrepidodera, Climate Change, Ensemble Modelling, Host Plants

\section{INTRODUCTION}

The potential effects of ongoing and future human-related climate change on biodiversity at both global and regional scales represent one of the most studied and debated issues of our epoch. More and more evidence has been found that relates global warming to detrimental changes in both the abiotic and biotic characteristics of a wide range of habitats, threatening a large number of animal and plant species (Bellard et al., 2012; Dullinger et al., 2012; Zhang et al., 2017; Archis et al., 2018; Iannella et al., 2018). The species prevalently inhabiting mountainous regions severely suffer from climate change, due to the associated rapid and dramatic modifications in the high-altitudes ecosystems (Inouye, 2008; Forrest et al., 2012; Li et al., 2016; Urbani et al., 2017; Rogora et al., 2018). In this context, Habitat Suitability Models (HSMs) (Guisan et al., 2017) represent a powerful investigation tool, whose huge increase of implementations in the last two decades has marked a noticeable break-through in conservation biogeography (Franklin, 2013). Indeed, the use of HSMs to investigate the factors which shape the potential distribution of species showing puzzling biogeographical patterns can provide useful insights (Acevedo et al., 2012; Iannella et al., 2017; Reino et al., 2017), especially in a climate change context. 
The Alticini tribe comprises small-to-medium-sized phytophagous Coleoptera from the Chrysomelidae family, subfamily Galerucinae, named 'flea beetles' because of the presence of a metafemoral extensor tendon that enables them to jump. They are probably the largest and most diversified tribe of Chrysomelidae, comprising about 550 genera and over 8000 species worldwide (Nadein \& Beždek 2014). Some genera spread over several zoogeographical regions, while others are strictly endemic to narrow areas. Nonetheless, even when characterized by limited distributions, genera or species-groups can differentiate in a high number of species (Biondi \& D'Alessandro 2008, D'Alessandro et al., 2014, 2016). Host plants for the Alticini tribe are known from almost all the vascular plant families, generally with high levels of specialization and close relation with the vegetation types (Jolivet \& Verma 2002; Biondi et al., 2015; D’Alessandro et al., 2018). The large number of species, the diversification of distribution ranges, the differentiation capability, the close relation with the vegetation types and the high levels of trophic specialization, make flea beetles sensitive to various environmental changes. Thus, flea beetles represent a good model for the investigation of evolutionary and biogeographical hypotheses and processes at different geographic scales (D'Alessandro et al., 2014, 2018; Urbani et al., 2015, 2017).

The flea beetle genus Neocrepidodera Heikertinger (Coleoptera: Chrysomelidae: Galerucinae: Alticini) is widespread, with about 100 species in the Palaearctic, Nearctic and Oriental regions. The Palaearctic taxa were revised by Biondi (1989, 1993), Konstantinov (1991), Konstantinov and Vandenberg (1996), Baselga and Novoa (2005), Baselga (2006) and Döberl (2010). This genus occurs in Europe with 30 species, according to the Pan-European Species Directories Infrastructure (PESI, 2018). The Western Palaearctic species are generally associated with medium and high elevations, and they show a high rate of endemism and vicariance deemed to be mainly linked with the Quaternary paleoclimatic events (Biondi 1989, 1993). 
Notwithstanding the noticeable peculiarities characterising the biogeography and ecology of these phytophagous beetles, no previous study implementing HSMs has been carried out on any Neocrepidodera species to investigate the relative distributional drivers.

Here, we used Ensemble Forecasting techniques (Araujo \& New, 2007), which permit the combination of multiple HSMs into a single Ensemble Model through different averaging criteria, to assess the potential future responses of three pairs of Neocrepidodera taxa to different climate change scenarios. Specifically, three Representative Concentration Pathways (RCPs), depicting increasing radiative forcing due to human-induced greenhouse gas (GHG) emissions, were considered for model projections.

Recent studies have highlighted the usefulness of including within the HSMs some predictors representing biotic interactions (Hof et al., 2012; Gherghel et al., 2018; Paiva-Silva et al., 2018) and/or the response of the resources used by animal species to the same abiotic variables used to model the species' potential distribution (Thuiller et al., 2018). Thus, for two selected pairs of closely related Neocrepidodera taxa, we implemented a nested modelling framework in which the predictions from Ensemble Models (EMs) built for the candidate host plants were included as predictors in the EMs built for the hosted flea beetles.

Moreover, we investigated, through measurements of niche overlap and statistical testing of niche divergence (Warren et al., 2008; Broennimann et al., 2012), whether the current distribution patterns characterizing the three pairs of Neocrepidodera taxa analysed could be linked to actual differences in their environmental and/or resource requirements. Results from such niche analysis could be helpful to clarify both the factors shaping the biogeography of the selected Neocrepidodera taxa and the potential differences in their response to climate change resulting from the performed Ensemble Forecasts. 


\section{MATERIALS AND METHODS}

\section{Study area and target taxa}

The study area encompasses three major mountainous massifs, which host almost all the occurrence records of the targeted taxa (Fig. 1): the Apennines, which run north-south across most of peninsular Italy; the Alps, whose arc covers Southern France, Northern Italy, Switzerland, Austria, Southern Germany and extends southeast in the Balkans; the Carpathians, going through Poland, Slovakia, Czech Republic, Austria, Hungary, Ukraine, Romania and Serbia.

We focused the analyses on three pairs of Neocrepidodera species and subspecies:

1) N. ligurica J. Daniel, 1904 versus N. melanostoma Redtenbacher, 1849, with the latter occurring in the Central and Northern Apennines, throughout the Alpine arc and in some localities of the Dynaric Alps, and the former occupying a narrow portion of the N. melanostoma distribution in the Ligurian, Maritime and Cottian Alps;

2) N. cyanescens cyanescens Duftschmid, 1825 versus $N$. cyanescens concolor K. Daniel, 1900, the first spread across the Eastern Alps and present in some localities in the Carpathians and in Transylvania, and the latter distributed in the Ligurian and Maritime Alps;

3) N. corpulenta Kutschera, 1860 versus N. rhaetica Kutschera, 1860; the former species is spread all along the Apennines chain, and present in some localities in the Balkans, in the Carpathians, in Transylvania and in the Western Alps, where it shares a parapatric zone with N. rhaetica, which replaces $N$. corpulenta in the rest of the Alpine arc.

We analysed the above-mentioned Neocrepidodera taxa by pairs to assess if differential responses to climatic and/or biotic factors could be linked to niche divergence phenomena between the closely related taxa forming each pair. This way, the environmental drivers contributing to their current disjunct (the two N. cyanescens subspecies), parapatric ( $N$. corpulenta - N. rhaetica) or nested $(N$. 
ligurica - N. melanostoma) distributions, as well as the potential shifts in response to climate change, could be better characterized.

Occurrence records (GPS resolution or exact locality) for the target taxa were retrieved from Maurizio Biondi's and other entomological collections, from the checklist of the Italian fauna (Biondi, 2006), from literature search and from the GBIF (Global Biodiversity Information Facility) database. In the latter case, occurrence records were scrutinized through both expert-based evaluation and literature search about the localities reported to host Neocrepidodera, to check their coherence with the known autoecology and biogeographical history of the considered taxa.

Considering available evidence about preferred host plants of some Neocrepidodera species (Biondi, 1993), we selected two species of Ranunculaceae, namely Aconitum lycoctonum L., 1753 emend. Koelle and A. napellus L., 1753 emend. Skalický, as candidate host plants for N. cyanescens cyanescens and $N$. cyanescens concolor, while for $N$. corpulenta and $N$. rhaetica we chose as candidate hosts two species of Asteraceae, namely Arnica montana L., 1753 and Doronicum austriacum Jacq., 1774. No plants were included as biotic predictors within the HSMs built for $N$. ligurica and $N$. melanostoma because less evidence about preferred hosts of these species is available so far.

Occurrence data for the selected plant species were gathered from the database of the CBNA (Conservatoire Botanique National Alpin), containing georeferenced records (ETRS89 reference system) from both France and other European countries; we considered only records with a minimum resolution of $1 \mathrm{~km}$ temporally ranging from the middle $1960 \mathrm{~s}$ to 2013 . Since the presence points of the Neocrepidodera taxa were recorded using the WGS84 geographic coordinate system, we projected them to the ETRS89 reference system in ArcMap 10.0 (ESRI 2011) before model building; thus, the occurrence datasets of Neocrepidodera and those of the candidate host plants shared the same reference system. Fig. 1 shows the distribution of presence points retrieved for the 


\section{Environmental variables}

\section{Current}

\section{Current} range of the study area.

Neocrepidodera taxa and for the host plants, while coordinates and sources of these occurrence records are listed in Supporting Information Table S1.

The available occurrences for each Neocrepidodera and plant taxon were spatially thinned through the "spThin" R package (Aiello-Lammens et al., 2015). For each taxon, three thinning iterations were performed setting 'thin.par' $=2 \mathrm{~km}$ to rarefy occurrences falling within neighbouring cells of the raster maps representing the considered predictors (see 'Environmental variables'). Then, the thinned dataframe with the highest number of remaining occurrences was selected for model building to preserve as information as possible about enviromental conditions at occurrence locations (Anderson \& Raza, 2010), given the limited amount of data available for some Neocrepidodera taxa (e.g. $N$. cyanescens concolor and N. ligurica).

The full occurrence datasets were instead used to obtain a representation of the geographic range of each Neocrepidodera taxon through $\alpha$-hull-based polygons, drawn by means of the $\mathrm{R}$ package “alphahull” (Beatriz Pateiro-López \& Alberto Rodríguez-Casal, 2010), which are less affected by biases in range estimates than the classic minimum convex polygons (Burgman \& Cox, 2003).

Nineteen downscaled bioclimatic variables from Worldclim version 1.4 (Hijmans et al., 2005; Dullinger et al., 2012) were chosen as climate-related candidate predictors and downloaded as raster files at 30 seconds resolution (i.e. approximately $1 \mathrm{~km}^{2}$ ). The downloaded rasters were projected from the original WGS84 reference system to ETRS89-LAEA (Lambert Azimuthal Equal Area) by means of the 'projectRaster' function from the "raster" R package (Hijmans et al., 2015), to match the metric reference system of the occurrence data (ETRS89) and preserve cell extent across the full latitudinal 
Presence of multicollinearity within the set of candidate predictors, which may lead to distortions in the estimation of model parameters and variable importance (Dormann, 2007; Crase et al., 2012; Dormann et al., 2013), was first checked by calculating the Pearson $r$ coefficient for each pair of variables across the study area. For the pairs with Pearson $|r|>0.7$, we kept the variable presumed to be more relevant to the species' ecology (Dormann et al., 2013; Brandt et al., 2017). Since hidden multicollinearity issues could still affect the data after having discarded the variables showing high pairwise correlations across the study area, further refinement on the candidate predictors was accomplished performing Variance Inflation Factor (VIF) analyses (Guisan et al., 2006, 2017) on the set of presence-pseudoabsence points used to build the HSMs (see 'Model building').

\section{Future}

Two time horizons (2050 and 2070) and three Representative Concentration Pathways (RCPs; RCP2.6, RCP4.5 and RCP8.5) (Meinshausen et al., 2011), based on the Rossby Centre Regional Climate Model RCA4 (Strandberg et al., 2014), were considered to investigate potential future distributional shifts of the target Neocrepidodera taxa in response to increasing GHGs concentration trajectories. As for the layers representing current climate, the WGS84-based rasters for the future scenarios were projected to ETRS89-LAEA through the 'projectRaster' function.

\section{Model building}

Model building was performed in R (R Core Team, 2018) through the package "biomod2" (Thuiller et al., 2016). The algorithms selected to build the HSMs were Generalized Linear Model (GLM), Generalized Additive Model (GAM) and Generalized Boosted Regression Models (GBM). For each algorithm, two-way interactions among predictors were allowed. With respect to the other relevant parameterization arguments, the default 'BIOMOD_ModelingOptions' settings were maintained for GLM ('quadratic' formula type, binomial error distribution with logit link function, and stepwise AIC as model selection criterium) and for GAM ('s_smoother' cubic-spline smoother and binomial error distribution with logit link function). For GBM, we set 5-fold cross-validation with 5000 fitted trees 
177 for each iteration, while other relevant parameters were maintained to the default values ('shrinkage' $178=0.001$, 'bag.fraction' $=0.5)$.

179 For both the target Neocrepidodera taxa and the selected host plants, pseudoabsences (hereafter, PAs) 180 were generated by means of a geographical exclusion strategy. First, a buffer ranging from $2 \mathrm{~km}$ to $181200 \mathrm{~km}$ around the thinned occurrences was generated for each taxon through the 'gBuffer' and 182 gDifference' functions of the "rgdal" R package (Bivand et al., 2014). Then, 10000 PAs were drawn at random within the obtained buffer polygon, after having clipped this latter to the boundaries of the study area to avoid the generation of PAs within raster cells with no values for the predictors (i.e. at sea). The clipping was performed through the 'Extract by Mask' function in ArcMap 10.0. Finally, 10 sets of 1000 PAs each were generated for HSMs calibration, randomly sampling without replacement from the previously drawn 10000 PAs.

The choice of a geographically-buffered PAs sampling, as well as the number of PAs sets and the sample size of these latter, was based on Barbet-Massin et al. (2012), who demonstrated that this approach is well suited to the algorithms we selected and that it ameliorates HSMs' accuracy when few occurrence records are available.

The chosen buffer distances were intended to avoid both the selection of PAs within the same cell of a presence point, or from the immediately contiguous cells, and the selection of PAs too far from presence localities. Indeed, PAs selected in a restricted region around occurrence localities would have increased the probability of obtaining low performing HSMs (VanDerWal et al., 2009); on the other hand, the generation of PAs within a noticeably broad area would have increased the probability of PAs falling in regions with bioclimatic conditions pronouncedly different than those of presence localities, potentially leading to over-simplified and artificially accurate HSMs (Chefaoui \& Lobo, 2008; VanDerWal et al., 2009).

The PAs sets generated for each taxon and the respective thinned occurrences were then joined in a 
function ('PA.strategy' set to 'user.defined'). Particularly, for each Neocrepidodera taxon and each host plant, the dataset for HSMs building comprised $90 \%$ of the available thinned occurrences and the ten sets of 1000 PAs previously generated. The remaining thinned occurrences were instead joined with 100 additional PAs randomly drawn within the buffer polygon, excluding the 10000 PAs already generated for model building, to build an independent evaluation dataset with which the continuous habitat suitability (hereafter, HS) predictions from the Ensemble Model (hereafter, EM) could be later compared to select a binarization threshold.

Values of the bioclimatic variables retained after the preliminary check of pairwise correlations, as well as suitability values from the wmean EMs (see 'Model evaluation and Ensemble Forecast') obtained for the candidate host plants, were extracted at occurrences and PAs points through the 'extract' function of the "raster" R package. Then, a VIF analysis was performed on these predictors through the 'vif.step' function of the "usdm" R package (Naimi, 2015), and the ones exceeding the recommended threshold of $\mathrm{VIF}=10$ (Guisan et al., 2017) were discarded from the modelling framework.

\section{Model evaluation and Ensemble Forecast}

Three iterations of a random split-sample cross-validation approach (Thuiller et al., 2016; Guisan et al., 2017) were performed on the datasets generated for HSMs building, each time using $80 \%$ of the data for model calibration and the remaining $20 \%$ as test data. Thus, 90 HSMs (i.e. 3 algorithms $* 3$ split-sample runs * 10 PAs sets) were finally built for each target taxon. Then, the HSMs whose predictions on the test data reached a chosen threshold value for both the True Skill Statistic (TSS) (Allouche et al., 2006) and the Area Under the Curve (AUC) of the Receiver Operating Characteristic Curve (ROC) (Fielding \& Bell, 1997; Phillips et al., 2006) were retained for the EM building process: the selected thresholds were TSS $\geq 0.7$ and AUC $\geq 0.8$. In the ensemble modelling step, we used the 'weighted mean of probabilities' (wmean) and the 'coefficient of variation of probabilities' (cv) algorithms implemented in the 'BIOMOD_EnsembleModeling' function. The wmean algorithm 
represents a form of weighted averaging in which the more an HSM attains high discrimination scores on test data the higher its predictions are weighted in the EM (Marmion et al., 2009); here, the contribution of the single HSMs to the wmean EM was weighted based on their TSS scores. The cv EM, instead, provides information about the degree of uncertainty in the EM building process. Indeed, it returns the coefficient of variation of HS values over the component HSMs (Thuiller et al., 2016), so that the higher the cv value at a certain pixel, the higher the variability in the HS values predicted for that pixel by the different HSMs.

The algorithm-independent randomization procedure of the BIOMOD modelling framework (Thuiller et al., 2009) was used to calculate the contribution of the single predictors within the obtained wmean EMs, setting the number of permutations to 3. Contribution scores from the 3 permutation runs were first averaged and then scaled to percent contributions (Bucklin et al., 2015).

The wmean EM for each of the 6 future scenarios ( 2 time horizons * 3 RCPs) was computed by means of the 'BIOMOD_EnsembleForecasting' function, projecting to that scenario the HSMs selected for ensemble modelling and then weighting their predictions based on the weights they achieved in the wmean EM built under current conditions. Successively, we used the 'BIOMOD_RangeSize' function to investigate potential shifts in suitable areas for the target Neocrepidodera taxa and the corresponding candidate host plants with respect to the current conditions (i.e. suitable areas lost, remaining stable or gained). Since this function needs binarized predictions (i.e. suitable vs unsuitable areas), we chose as binarization approach the maximisation of the TSS (max-TSS), computed by means of the 'Find.Optim.Stat' function comparing the wmean EM continuous predictions with the previously set-aside evaluation data. This is reported to be an appropriate binarization criterium when dealing with presence-background HSMs (Liu et al., 2013). The obtained thresholds are listed in Supporting Information Text S1.

The binarized raster maps for the current scenario and those representing the predicted HS shifts within the future scenarios were converted to shapefiles in ArcMap 10.0. Then, the 'Intersect' 
function of ArcMap 10.0 was used to extract, for each Neocrepidodera - host plant pair, the overlap polygons representing: 1) areas predicted to be suitable for both the considered flea beetle and the corresponding host plant under the current scenario, and 2) the different combinations of the Stable and Gain categories, representing areas predicted to be suitable in the projection scenario for both the flea beetle and the candidate host. The extent of these overlap polygons was then computed to quantify the effect of future warming conditions on the potential co-occurrence of the target Neocrepidodera taxa and the respective candidate hosts.

\section{Niche analysis}

In order to understand how the relative positions of the considered Neocrepidodera taxa in the environmental space could relate to their current distribution patterns, we implemented the 'PCAenv' approach described in Broennimann et al. (2012). The set of input predictors used to build the HSMs was thus reduced to two uncorrelated principal components, based on which kernel-smoothed densities of occupancy of the taxa in the environmental space were built. Moreover, for each pair of Neocrepidodera taxa, biplots were produced through the "factoextra" R package (Kassambara \& Mundt, 2017) to show the contribution of the input predictors along the two principal component axes.

The Schoener's D metric (Schoener, 1970; Warren et al., 2008) was calculated, through the 'ecospat.niche.overlap' function of the "ecospat" R package (Di Cola et al., 2017), to assess the degree of niche overlap within each pair of Neocrepidodera taxa. The obtained niche overlap values were statistically tested first for the niche equivalency hypothesis (Warren et al., 2008; Broennimann et al., 2012) through the 'ecospat.niche.equivalency.test' function, and then for the more conservative niche similarity hypothesis (Warren et al., 2008; Broennimann et al., 2012) by means of the 'ecospat.niche.similarity.test' function. For both tests, the observed niche overlap is compared to the $95^{\text {th }}$ percentile of the null distribution built through the specific randomization procedure (1000 
274 pseudo-replicates for both tests): if the observed $D$ falls outside this interval, the null hypothesis can 275 be rejected.

\section{RESULTS}

277 Nine bioclimatic variables were retained as candidate predictors after the check for multicollinearity 278 across the entire study area (see Supporting Information Table S2): BIO2 (Mean diurnal temperature 279 range), BIO3 (Isothermality), BIO4 (Temperature seasonality), BIO5 (Maximum temperature of 280 warmest month), BIO6 (Minimum temperature of coldest month), BIO8 (Mean temperature of 281 wettest quarter), BIO17 (Precipitation of driest quarter), BIO18 (Precipitation of warmest quarter) 282 and BIO19 (Precipitation of coldest quarter). The VIF analyses successively performed on the 283 presence-pseudoabsence datasets led to the final sets of uncorrelated predictors listed in Table 1.

284 The number of residual occurrences after the spatial thinning for the target Neocrepidodera taxa and 285 the candidate hosts, along with the countries hosting these presence records, are reported in 286 Supporting Information Table S3, while Table 2 summarizes the percent importance scores obtained 287 for the relevant predictors within the Ensemble Models (EMs) built for the host plants and the 288 Neocrepidodera. 
290 Table 1. Predictors selected to build the HSMs for the target Neocrepidodera taxa and the candidate host plants. HS = Habitat Suitability

\begin{tabular}{|c|c|}
\hline Host plants & Predictors \\
\hline $\begin{array}{c}\text { Aconitum lycocotnum } \\
\text { Aconitum napellus } \\
\text { Arnica montana } \\
\text { Doronicum austriacum }\end{array}$ & BIO3; BIO4; BIO6; BIO8; BIO18; BIO19 \\
\hline Neocrepidodera & Predictors \\
\hline $\begin{array}{c}\text { N. ligurica } \\
\text { melanostoma }\end{array}$ & BIO3; BIO4; BIO6; BIO8; BIO18; BIO19 \\
\hline $\begin{array}{c}\text { N. cyanescens concolor } \\
\text { N. cyanescens cyanescens }\end{array}$ & BIO3; BIO4; BIO6; BIO8; BIO18; Aconitum lycoctonum HS; Aconitum napellus HS \\
\hline $\begin{array}{c}\text { N. corpulenta } \\
\text { N. rhaetica }\end{array}$ & BIO3; BIO4; BIO6; BIO8; BIO18; BIO19; Arnica montana HS; Doronicum austriacum HS \\
\hline
\end{tabular}


Table 2. Averaged percent importance scores of: the three most contributing bioclimatic predictors for Aconitum lycoctonum, Aconitum napellus, Arnica montana and Doronicum austriacum; the four most contributing bioclimatic predictors for each target Neocrepidodera taxon, along with host plant Habitat Suitability (HS) for N. cyanescens concolor, N. cyanescens cyanescens, N. corpulenta and N. rhaetica.

\begin{tabular}{|c|c|c|c|c|c|}
\hline \multicolumn{6}{|c|}{ Candidate Host Plants Ensemble Models } \\
\hline Taxon & Predictor & $\begin{array}{c}\text { Percent } \\
\text { Contribution }\end{array}$ & Taxon & Predictor & $\begin{array}{c}\text { Percent } \\
\text { Contribution }\end{array}$ \\
\hline \multirow{3}{*}{$\begin{array}{l}\text { Aconitum } \\
\text { Iycoctonum }\end{array}$} & $\mathrm{BIO6}$ & 33.6 & \multirow{3}{*}{$\begin{array}{l}\text { Aconitum } \\
\text { napellus }\end{array}$} & $\mathrm{BIO6}$ & 46.0 \\
\hline & $\mathrm{BIO} 18$ & 27.0 & & $\mathrm{BIO8}$ & 37.1 \\
\hline & $\mathrm{BIO}$ & 18.5 & & $\mathrm{BIO4}$ & 11.6 \\
\hline \multirow{3}{*}{$\begin{array}{c}\text { Arnica } \\
\text { montana }\end{array}$} & $\mathrm{BIO6}$ & 37.5 & \multirow{3}{*}{$\begin{array}{l}\text { Doronicum } \\
\text { austriacum }\end{array}$} & $\mathrm{BIO6}$ & 39.0 \\
\hline & $\mathrm{BIO4}$ & 21.6 & & $\mathrm{BIO}$ & 19.1 \\
\hline & $\mathrm{BIO}$ & 18.4 & & $\mathrm{BIO} 4$ & 16.0 \\
\hline \multicolumn{6}{|c|}{ Neocrepidodera Ensemble Models } \\
\hline Taxon & Predictor & $\begin{array}{c}\text { Percent } \\
\text { Contribution }\end{array}$ & Taxon & Predictor & $\begin{array}{c}\text { Percent } \\
\text { Contribution }\end{array}$ \\
\hline \multirow{4}{*}{ N. ligurica } & $\mathrm{BIO} 4$ & 22.6 & \multirow{4}{*}{ N. melanostoma } & $\mathrm{BIO6}$ & 34.4 \\
\hline & $\mathrm{BIO6}$ & 21.0 & & $\mathrm{BIO} 18$ & 21.2 \\
\hline & $\mathrm{BIO3}$ & 18.6 & & $\mathrm{BIO} 4$ & 18.7 \\
\hline & $\mathrm{BIO19}$ & 16.5 & & $\mathrm{BIO3}$ & 10.6 \\
\hline \multirow{6}{*}{$\begin{array}{l}\text { N. cyanescens } \\
\text { concolor }\end{array}$} & $\begin{array}{c}\text { Aconitum } \\
\text { lycoctonum HS }\end{array}$ & 28.7 & \multirow{6}{*}{$\begin{array}{l}\text { N. cyanescens } \\
\text { cyanescens }\end{array}$} & $\mathrm{BIO} 18$ & 43.3 \\
\hline & $\mathrm{BIO6}$ & 18.9 & & $\mathrm{BIO6}$ & 21.9 \\
\hline & $\mathrm{BIO}$ & 16.2 & & $\mathrm{BIO} 2$ & 9.3 \\
\hline & $\mathrm{BIO} 18$ & 14.0 & & $\mathrm{BIO} 8$ & 8.5 \\
\hline & $\mathrm{BIO8}$ & 9.1 & & $\begin{array}{c}\text { Aconitum } \\
\text { napellus HS }\end{array}$ & 8.1 \\
\hline & $\begin{array}{l}\text { Aconitum } \\
\text { napellus HS }\end{array}$ & 4.5 & & $\begin{array}{c}\text { Aconitum } \\
\text { Iycoctonum HS }\end{array}$ & 2.1 \\
\hline \multirow{6}{*}{ N. corpulenta } & $\mathrm{BIO8}$ & 18.9 & \multirow{6}{*}{ N. rhaetica } & $\mathrm{BIO6}$ & 19.9 \\
\hline & $\mathrm{BIO}$ & 18.0 & & $\mathrm{BIO}$ & 19.5 \\
\hline & $\mathrm{BIO4}$ & 15.5 & & $\mathrm{BIO}$ & 14.2 \\
\hline & $\mathrm{BIO19}$ & 13.8 & & $\mathrm{BIO4}$ & 10.5 \\
\hline & $\begin{array}{c}\text { Arnica } \\
\text { montana } \mathrm{HS}\end{array}$ & 8.4 & & $\begin{array}{c}\text { Arnica } \\
\text { montana } \mathrm{HS}\end{array}$ & 9.0 \\
\hline & $\begin{array}{c}\text { Doronicum } \\
\text { austriacum HS }\end{array}$ & 3.4 & & $\begin{array}{c}\text { Doronicum } \\
\text { austriacum HS }\end{array}$ & 8.9 \\
\hline
\end{tabular}


Apart from Aconitum lycoctonum, for which precipitation of the warmest quarter (BIO18) obtained the second highest importance score, temperature-linked variables, particularly minimum temperature of the coldest month (BIO6), clearly resulted as the most important predictors for all the candidate host plants (Table 2). From the corresponding partial response curves, Habitat Suitability (HS) for the host plants appears to decrease, once the remaining predictors have been set to their mean value, as temperature, or its seasonality (BIO4), increases (Supporting Information Fig. S1). Temperature-linked variables resulted as predominant predictors also for $N$. ligurica and $N$. melanostoma, with the first species showing comparable importance scores for BIO4 and BIO6 (Table 2), and the latter being instead more markedly dependent upon BIO6. Different partial responses to BIO6 emerged for the two species, with the response curve obtained for $N$. ligurica being monotonically decreasing and the one obtained for N. melanostoma being more bell-shaped-like (Supporting Information Fig. S2). Considering the two pairs of Neocrepidodera taxa for which suitability for the respective candidate hosts was included among the predictors, only from the EM built from $N$. cyanescens concolor an host plant, namely Aconitum lycoctonum, resulted as the most important predictor (Table 2). Nonetheless, the three-dimensional response surfaces represented in Supporting Information Figs. S5-6 show that, at the least for one of the candidate host plants, the combined effect of host suitability and of the most important bioclimatic predictor, once all the remaining predictors have been set to their mean value, produced higher predicted HS values than the single predictors individually did (cf. Supporting Information Figs. S3-4). Indeed, for both the $N$. cyanescens subspecies, higher suitability values for Aconitum lycoctonum synergistically increase suitability for the flea beetles in combination with BIO6 ( $N$. cyanescens concolor) and, even though less clearly, with BIO18 (N. cyanescens cyanescens) (Fig. S5). This pattern did not emerge considering the combined effect of HS for Aconitum napellus and the same bioclimatic predictors. With respect to the pair $N$. corpulenta $-N$. rhaetica, a positive effect on flea beetle suitability emerged from the combination of Arnica montana suitability and BIO6 for N. rhaetica and, to a lesser extent, 
320 from the combination of Doronicum austriacum suitability and mean temperature of the wettest quarter (BIO8) for N. corpulenta (Fig. S6).

Continuous maps resulting from the cv EMs built for the current scenario were reported in Supporting Information Fig. S7. The coefficient of variation among the predictions of the component HSMs is less than 0.4 across most of the study area for $N$. melanostoma, $N$. cyanescens cyanescens and $N$. rhaetica, while wider areas with $\mathrm{cv}>0.4$ emerged for $N$. ligurica, N. cyanescens concolor and $N$. corpulenta, primarily outside their currently occupied range (see Figs. 2a, 3a, 4a)

The binarized HS under the current scenario for the three considered Neocrepidodera pairs and the respective predicted HS shifts under the different 2070 RCP scenarios are shown in Figs. 2-4, while predicted HS shifts for 2050 under the different RCPs were reported in Supporting Information Figs. S8-10.

The core of $N$. ligurica density of occurrence in the bioclimatic space corresponds to a peripherical portion of the wider density of occurrence of $N$. melanostoma (Fig. 5a2), resulting in markedly broader suitable areas for this latter species also in geographical space (Figs. 2a-b). The niches of $N$. ligurica and N. melanostoma, whose overlap value was $D=0.054$, appeared not to be equivalent (P $<0.001$ in the niche equivalency test). However, when tested for niche divergence through the niche similarity test, the niches of the two species resulted not more different than expected by chance $(\mathrm{P}=$ 0.652), based on differences in the bioclimatic conditions characterising the respective ranges.

Neocrepidodera cyanescens concolor and $N$. cyanescens cyanescens showed null niche overlap $(D=$ 0) reflected by strong divergences in their occupancy of the environmental space (Fig. 5b2), which is coherent with the mostly different areas predicted as suitable for them under the current scenario (Figs. 3a-b). The niches of the two subspecies are clearly differentiated along the first principal component, to which high contribution was given by BIO6 (Figs. 5b1-2). Moreover, the centre of the occurrence density for $N$. cyanescens concolor is more shifted towards positive values of the second 
contribution given by suitability for Aconitum lycoctonum to this axis (Fig. 5b1). Even though the niche equivalency test rejected the hypothesis of the niches of the two $N$. cyanescens subspecies being equivalent $(\mathrm{P}<0.001)$, the niche similarity test did not permit to infer a significant divergence once the differences in background conditions were considered $(\mathrm{P}=0.598)$.

The niche overlap value for $N$. corpulenta and $N$. rhaetica was $D=0.201$, reflected by their densities of occurrence showing noticeable overlap but clearly separated centres (Fig. 5c2). As for the two previous pairs of Neocrepidodera, according to the niche equivalency test the modelled niches of $N$. corpulenta and $N$. rhaetica are not equivalent $(\mathrm{P}<0.001)$. Anyway, the result of the niche similarity test $(\mathrm{P}=0.562)$ did not permit to reject the null hypothesis of the niches being less different than expected based on the environmental conditions in the respective ranges.

Neocrepidodera ligurica, $N$. cyanescens concolor, $N$. corpulenta and $N$. rhaetica were predicted to lose by 2070 the great majority of currently suitable areas, especially under RCP8.5 (Figs. 2g, 3g, 4g, 4h). N. cyanescens cyanescens, instead, was predicted to maintain under all the RCPs the major part of suitable areas corresponding to the core of its current range (Figs. 3d, 3f, 3h); moreover, it was predicted to gain broad suitable areas in Central and Eastern Alps under all the RCPs and in the Carpathians under RCP2.6 (Fig. 3d). Finally, N. melanostoma was predicted to maintain stable areas in Eastern Alps and potentially gain broad suitable areas even under the more pronounced warming scenarios (Figs. 2d, 2f, 2h). Anyway, most of this predicted gain corresponds to areas located far away from the current range of the species, while large portions of the currently occupied territories were predicted to become unsuitable under RCP4.5 and RCP8.5 (Figs. 2f, 2h)

The variation in the extent of overlapping suitable area between each of the two $N$. cyanescens subspecies and the candidate Aconitum hosts from the current scenario to 2050 and 2070 under the three RCPs was reported, respectively, in Fig. 6a and Fig. 6c. Differently, Fig. 6b and Fig. 6d show the variation in the percent extent of overlapping suitable area with respect to the overall suitable area for the flea beetle under the different RCPs in 2050 and 2070. The same information for $N$. corpulenta 
and $N$. rhaetica with respect to Doronicum austriacum and Arnica montana was summarized in Figs. 7a-d.

The overlap of suitable areas for $N$. cyanescens concolor and the two Aconitum species was predicted to decrease both in 2050 and 2070 (Figs. 6a, 6c), with a clear negative trend along the RCP gradient in 2070. The percentage of suitable area for $N$. cyanescens concolor hosting suitable conditions also for A. lycoctonum was predicted to remain close to its current value $(\sim 10 \%)$ under all the three RCPs, both in 2050 and 2070, while a marked decrease in the percent extent of overlapping suitable areas for N. cyanescens concolor and A. napellus was predicted both in 2050 (except under RCP4.5) and in 2070 (Figs. 6b, 6d).

Considering $N$. cyanescens cyanescens, both the extent of overlapping suitable areas with the two Aconitum species (Figs. 6a, 6c) and the percentage of suitable area for the flea beetle hosting suitable conditions also for the host plants (Fig. 6b, 6d) were predicted to decrease with respect to current conditions both in 2050 and in 2070, with clearly decreasing trends along the RCP gradient emerging from projections to 2070 .

The extent of overlapping suitable areas for the pairs $N$. corpulenta - A. montana and N. corpulenta - D. austriacum was predicted to greatly decrease with respect to current conditions under RCP4.5 and RCP8.5, especially in 2070 (Figs. 7a, 7c). Under RCP 8.5, in 2070 the percentage of suitable area for $N$. corpulenta predicted to be suitable also for the candidate host fell to 0 both for $A$. montana and for D. austriacum (Fig. 7d). The extent of overlapping suitable areas for $N$. rhaetica and $D$. austriacum was almost null under the current scenario as well as in 2050 and 2070 under the different RCPs (Fig. 7a, 7c). Finally, considering the pair N. rhaetica - A. montana, a decrease in both the net extent and the relative percentage of overlapping suitable area with respect to the current conditions emerged for all the future scenarios, except in 2050 under RCP8.5 because of the stable and gained areas predicted under this scenario for $N$. rhaetica in Central and Eastern Alps (see Fig. S10), regions which are suitable to $A$. montana as well (results not shown). 


\section{DISCUSSION}

396

Given the tight bound of the considered Neocrepidodera taxa with the mountainous and alpine ecosystems (Biondi, 1993), the identification of the variables shaping and constraining their environmental niches represents an important first step to shed light on the potential future distributional shifts of these flea beetles in response to the ongoing and future climate change (Bibi et al., 2018; Lamprecht et al., 2018; Rogora et al., 2018).

The current distributional patterns of the Neocrepidodera taxa within each pair are reflected in the environmental niches depicted through both the Ensemble Modelling approach and the PCA-env procedure.

Neocrepidodera ligurica occurs in a peripheric portion, in Western Alps, of the broader geographic range of $N$. melanostoma, and the density of occurrence of the former species in the environmental space indeed falls at the borders of that of $N$. melanostoma (Fig. 5a2). The narrow climatic niche of N. ligurica, associated with its restricted current geographic range (Fig. 2a), could represent a major threat to the future conservation of this species in the face of climate change (Murray et al., 2010; Brown \& Yoder, 2015; Brunetti et al., 2019). Indeed, most of the areas predicted to be suitable outside the species range under the current scenario are very distant from the currently occupied ones, and thus the former would be difficulty colonized; moreover, most of them are predicted to be lost even under moderate warming (Figs. 2, S8). Differently, N. melanostoma seems to be threatened by climate change only to some extent: in fact, notwithstanding the populations occurring in Western Alps may suffer from the loss of suitable areas in the next decades, especially considering RCP4.5 and RCP8.5, the obtained Ensemble Forecasts to 2070 predicted the gain of broad suitable areas in the northeastern portion of the study area under all the considered RCPs. 
417 The two N. cyanescens subspecies were found to occupy clearly differentiated environmental niches 418 (Figs. 5b1-2). Nonetheless, the negative result of the niche similarity test indicates that such 419 differentiation is due to the differences in the environmental conditions the two subspecies experience 420 in their respective ranges, suggesting that their divergence might have been prompted by allopatric 421 processes rather than directly by niche divergence (Pyron, 2009; McCormack et al., 2010; Alvarado422 Serrano, 2014). Neocrepidodera cyanescens concolor resulted to be potentially threatened by climate 423 change as dramatically as $N$. ligurica, with major loss of currently suitable areas under RCP4.5 and 424 RCP8.5 (Figs. 3, S9). Differently, N. cyanescens cyanescens will likely maintain wide suitable areas within the core of its current range and it is also predicted to gain some peripherical territories under all the considered scenarios, which bodes well for the conservation of its current populations, at least in Eastern Alps.

The density of occurrence in environmental space modelled for $N$. corpulenta and $N$. rhaetica highlighted the existence of a certain range of environmental conditions suitable to both species, even though the respective maximum density zones are clearly separated (Fig. 5c2). This is coherent with the existence of a parapatric area in Western Alps where the two species currently co-occur (Iannella et al., 2017; Reino et al., 2017). With respect to the predicted suitability shifts, both species may face direct threats to the persistence of their populations in the next future: indeed, the patches of stable or gained suitable areas predicted for the two species mainly under RCP 2.6 and RCP4.5, many of which unlikely to be colonized due to their distance from the currently occupied areas, would difficultly counterbalance the overwhelming loss of suitable territories across most of the species' range (Figs. 4, S10).

The contribution of host plant suitability resulted to be preponderant only within the Ensemble Model obtained for $N$. cyanescens concolor (Table 2). Nonetheless, the three-dimensional response surfaces representing the combined contribution of host suitability and influential bioclimatic variables (Figs. 
of insect-plant co-occurrence may require particular attention for the conservation of some Neocrepidodera taxa. This is particularly true considering A. lycocotum with respect to the two $N$. cyanescens subspecies and $A$. montana with respect to $N$. rhaetica.

It is important to notice the predicted future decrease in the extent of potential co-occurrence areas for almost all the considered insect-plant pairs, especially under the more pronounced warming scenarios (Figs. 6-7). This could represent a double jeopardy for those flea beetles predicted to experience a noticeable contraction of their potential distribution in response to warming climate, as $N$. cyanescens concolor, $N$. corpulenta and $N$. rhaetica. Indeed, even though A. montana and D. austriacum did not unequivocally emerge as important predictors of $N$. corpulenta and $N$. rhaetica suitability, the reduction of potential co-occurrence under almost all the considered future scenarios (Fig. 7) could represent a trend of contraction in response to warming climate common to other highaltitude Asteraceae species not considered here (Dullinger et al., 2012) and possibly associated to these two flea beetles in a stronger manner than D. austriacum and A. montana.

Thus, the inclusion of variables related to biotic interactions within the HSMs confirmed to be, even though not completely resolutive in our study, a useful and informative praxis when applying these models to conservation biogeography (Van der Putten et al., 2010; Hof et al., 2012; Franklin, 2013; Gherghel et al., 2018; Thuiller et al., 2018).

From a conservation perspective, it should be pointed out that some of the targeted Neocrepidodera taxa will probably require thoughtful prioritization measures in the next future. The restricted current distribution of $N$. ligurica and $N$. cyanescens concolor, the narrow bioclimatic niche of the former, the strong reduction of potential co-occurrence with A. lycoctonum predicted for the latter and the dependence of both taxa on temperature-related variables (see Table 1), all represent important alarm bells for the persistence of their current populations. In fact, restricted ranges and sensitivity to changes in temperature regimes already emerged as strong risk factors from previous studies on other orophilous endemic insects (Urbani et al., 2017; Brunetti et al., 2019). N. rhaetica and N. corpulenta 
467 should be given appropriate consideration as well: indeed, notwithstanding they are more widely 468 distributed than the above-cited taxa, the remaining suitable areas predicted under future warming 469 conditions resulted to be far less extended and more fragmented than under current climate.

470 However, it should also be mentioned that the representation of the environmental niche emerging 471 from the implemented modelling framework may not properly represent the full fundamental niche 472 of the considered taxa. In fact, the lack of absence and/or abundance data does not permit to have a 473 complete quantification of a species niche (Brotons et al., 2004; Howard et al., 2014); moreover, 474 "proximal" factors other than potential host availability, like dispersal capabilities and population 475 dynamics, could have hampered the target taxa to colonize regions with suitable conditions and reach 476 the equilibrium with the environment (Guisan et al., 2017).

477 In conclusion, even though detailed prioritization indications could not be provided based only on 478 HSMs forecasting (Sofaer et al., 2018; Peterson et al., 2018), our results highlighted the need to 479 deepen the knowledge about the threats that Neocrepidodera and other phytophagous insects will 480 face in the future decades. It is of the utmost importance to keep on investigating the potential effects 481 of climate change on both fauna and flora of mountainous ecosystems, encouraging the integration, 482 when possible, of modelling, experimental and field-based research.

\section{ACKNOWLEDGEMENTS}

We are grateful to the Editor and the two anonymous Reviewers for their insightful comments, which permitted us to improve the clearness of this manuscript. 
484

485

486

487

\section{Figures captions}

Figure 1. European biogeographical regions, as defined by the European Environmental Agency (EEA), with a zoom on the study area, showing the altitudinal zonation and the occurrences for the six target Neocrepidodera taxa and the candidate host plants.

Figure 2. Suitable areas under the current scenario, obtained from the predictions of the weighted mean Ensemble Model, and $\alpha$-hull-based current range (hatched polygons) for (a) N. ligurica and (b) N. melanostoma; predicted shifts in habitat suitability by 2070 under RCPs $2.6,4.5$ and 8.5 for (c), (e) and (g) N. ligurica, and (d), (f) and (h) N. melanostoma, respectively.

Figure 3. Suitable areas under the current scenario, obtained from the predictions of the weighted mean Ensemble Model, and $\alpha$-hull-based current range (hatched polygons) for (a) $N$. cyanescens concolor and (b) N. cyanescens cyanescens; predicted shifts in habitat suitability by 2070 under RCPs 2.6, 4.5 and 8.5 for (c), (e) and (g) N. cyanescens concolor, and (d), (f) and (h) N. cyanescens cyanescens, respectively.

Figure 4. Suitable areas under the current scenario, obtained from the predictions of the weighted mean Ensemble Model, and $\alpha$-hull-based current range (hatched polygons) for (a) $N$. corpulenta and (b) N. rhaetica; predicted shifts in habitat suitability by 2070 under RCPs 2.6, 4.5 and 8.5 for (c), (e) and (g) N. corpulenta, and (d), (f) and (h) N. rhaetica, respectively.

Figure 5. Contributions of the input predictors along the first two principal components ('PCA-env', Broennimann et al., 2012) for: (a1) N. ligurica and N. melanostoma; (b1) N. cyanescens concolor and $N$. cyanescens cyanescens; (c1) N. corpulenta and $N$. rhaetica. Density of occurrence in the environmental space defined by the principal components for: (a2) N. ligurica (Sp1) and $N$. melanostoma (Sp2); (b2) N. cyanescens concolor (Sp1) and N. cyanescens cyanescens (Sp2); (c2) N. corpulenta (Sp1) and $N$. rhaetica (Sp2). Within the density plots, solid contour lines represent the full environmental background and dashed contour lines represent $50 \%$ of the background environment. 
508 Figure 6. Variation in the extent of overlapping suitable area between the two $N$. cyanescens 509 subspecies and the corresponding candidate host plants (Aconitum lycoctonum and A. napellus) from 510 the current scenario to 2050 (a) and 2070 (c) under the three RCPs; variation in the percent extent of 511 overlapping suitable area with respect to the overall suitable area for the flea beetle under the different 512 RCPs in 2050 (b) and 2070 (d).

513 Figure 7. Variation in the extent of overlapping suitable area between N. corpulenta, N. rhaetica and 514 the corresponding candidate host plants (Arnica montana and Doronicum austriacum) from the 515 current scenario to 2050 (a) and 2070 (c) under the three RCPs; variation in the percent extent of 516 overlapping suitable area with respect to the overall suitable area for the flea beetle under the different 517 RCPs in 2050 (b) and 2070 (d). 
519

\section{References}

Acevedo, P., Jiménez-Valverde, A., Melo-Ferreira, J., Real, R. \& Alves, P. C. (2012) Parapatric species and the implications for climate change studies: a case study on hares in Europe. Global Change Biology, 18, 1509-1519.

Aiello-Lammens, M. E., Boria, R. A., Radosavljevic, A., Vilela, B. \& Anderson, R. P. (2015) spThin: an R package for spatial thinning of species occurrence records for use in ecological niche models. Ecography, 38, 541-545.

Allouche, O., Tsoar, A. \& Kadmon, R. (2006) Assessing the accuracy of species distribution models: prevalence, kappa and the true skill statistic (TSS). Journal of Applied Ecology, 43, 1223-1232.

Alvarado-Serrano, D. F. \& Knowles, L. L. (2014) Ecological niche models in phylogeographic studies: applications, advances and precautions. Molecular Ecology Resources, 14, 233-248.

Anderson, R. P. \& Raza, A. (2010) The effect of the extent of the study region on GIS models of species geographic distributions and estimates of niche evolution: preliminary tests with montane rodents (genus Nephelomys) in Venezuela. Journal of Biogeogaphy, 37, 1378-1393.

Araujo, M. B. \& New, M. (2007) Ensemble forecasting of species distributions. Trends Ecol Evol, 22, 42-47.

Archis, J. N., Akcali, C., Stuart, B. L., Kikuchi, D., \& Chunco, A. J. (2018) Is the future already here? The impact of climate change on the distribution of the eastern coral snake (Micrurus fulvius). PeerJ, $\mathbf{6}$, e4647.

Barbet-Massin, M., Jiguet, F., Albert, C. H., \& Thuiller, W. (2012) Selecting pseudo-absences for species distribution models: how, where and how many?. Methods in ecology and evolution, 3, 327-338.

Baselga, A. (2006) The Northeastern Palaearctic light coloured Neocrepidodera Heikertinger, 1911 (Coleoptera: Chrysomelidae), with description of a new species. Zootaxa, 1246, 55-68.

Baselga, A. \& Novoa, F. (2005) The Western Palaearctic Neocrepidodera (Coleoptera: Chrysomelidae) of the N. impressa and N. ferruginea species groups. Annals of the Entomological Society of America, 98, 896-907. 
Bibi, S., Wang, L., Li, X., Zhou, J., Chen, D., \& Yao, T. (2018) Climatic and associated cryospheric, biospheric, and hydrological changes on the Tibetan Plateau: a review. International Journal of Climatology, 38, e1-e17.

Biondi, M. (1989) Classification and phylogenesis of the Western Palaearctic species of the genus Asiorestia Jacobson (Coleoptera, Chrysomelidae, Alticinae). Entomography, 6, 519-529.

Biondi, M. (1993) Revisione del sottogenere Asiorestia Jacob. s. str. (Coleoptera Chrysomelidae Alticinae). Bollettino del Museo Civico di Storia Naturale di Verona, 17, 1-55.

Biondi, M. (2006) Chrysomelidae Alticinae. Checklist and distribution of the Italian fauna (ed. by Ruffo, S. \& Stoch, F). Memorie del Museo civico di storia naturale di Verona, 2.Serie, Sezione Scienze della Vita 17 , with CD-ROM.

Biondi, M. \& D'Alessandro, P. (2008) Taxonomical revision of the Longitarsus capensis species-group: an example of Mediterranean-southern African disjunct distributions (Coleoptera: Chrysomelidae). European Journal of Entomology, 115, 719-736.

Biondi, M., Urbani, F. \& D’Alessandro, P. (2015) Relationships between the geographic distribution of phytophagous insects and different types of vegetation: a case study of the flea beetle genus Chaetocnema (Coleoptera: Chrysomelidae) in the Afrotropical region. European Journal of Entomology, 112, 311-327.

Bivand, R., Keitt, T., Rowlingson, B., \& Pebesma, E. (2014) rgdal: Bindings for the geospatial data abstraction library. $\mathrm{R}$ package version $0.8-16$

Brandt, L.A., Benscoter, A.M., Harvey, R., Speroterra, C., Bucklin, D., Romañach, S.S., Watling, J.I. \& Mazzotti, F.J. (2017) Comparison of climate envelope models developed using expert-selected variables versus statistical selection. Ecological Modelling, 345, 10-20.

Broennimann, O., Fitzpatrick, M. C., Pearman, P. B., Petitpierre, B., Pellissier, L., Yoccoz, N. G., Thuiller, W., Fortin, M. J., Randin, C., Zimmermann, N. E., Graham, C. H. \& Guisan, A. (2012) Measuring 

ecological niche overlap from occurrence and spatial environmental data. Global Ecology and Biogeography, 21, 481-497.

Brotons, L., Thuiller, W., Araújo, M. B., \& Hirzel, A. H. (2004) Presence-absence versus presence-only modelling methods for predicting bird habitat suitability. Ecography, 27, 437-448.

Brown, J. L. \& Yoder, A. D. (2015) Shifting ranges and conservation challenges for lemurs in the face of climate change. Ecology and Evolution, 5, 1131-1142.

Brunetti, M., Magoga, G., lannella, M., Biondi, M., \& Montagna, M. (2019) Phylogeography and species distribution modelling of Cryptocephalus barii (Coleoptera: Chrysomelidae): is this alpine endemic species close to extinction?. ZooKeys, 856, 3-25.

Bucklin, D. N., Basille, M., Benscoter, A. M., Brandt, L.A., Mazzotti, F. J., Romanach, S. S., Speroterra, C. \& Watling, J. I. (2015) Comparing species distribution models constructed with different subsets of environmental predictors. Diversity and Distributions, 21, 23-35.

Burgman, M. A. \& Fox, J. C. (2003) Bias in species range estimates from minimum convex polygons: implications for conservation and options for improved planning. Animal Conservation forum, 6, 1928

Chefaoui, R. M. \& Lobo, J.M. (2008) Assessing the effects of pseudo-absences on predictive distribution model performance. Ecological Modelling, 210, 478-486.

Crase, B., Liedloff, A. C. \& Wintle, B.A. (2012) A new method for dealing with residual spatial autocorrelation in species distribution models. Ecography, 35, 879-888.

D’Alessandro, P., Urbani, F. \& Biondi, M. (2014) Biodiversity and biogeography in Madagascar: revision of the endemic flea beetle genus Neodera Duvivier, 1891 with description of 19 new species (Coleoptera, Chrysomelidae, Galerucinae, Alticini). Systematic Entomology, 39, 710-748.

D’Alessandro, P., Samuelson, A. \& Biondi, M. (2016) Taxonomic revision of the genus Arsipoda Erichson, 1842 (Coleoptera, Chrysomelidae) in New Caledonia. European Journal of Taxonomy, 230, 1-61. 
D’Alessandro, P., lannella, M., Frasca, R. \& Biondi, M. (2018) Distribution patterns and habitat preference for the genera-group Blepharida s.I. in Sub-Saharan Africa (Coleoptera: Chrysomelidae: Galerucinae: Alticini). Zoologischer Anzeiger-A Journal of Comparative Zoology, 277, 23-32.

Di Cola, V., Broennimann, O., Petitpierre, B., Breiner, F. T., D'Amen, M., Randin, C., Engler, R., Pottier, J., Pio, D., Dubuis, A., Pellissier, L., Mateo, R .G., Hordijk, W., Salamin, N. \& Guisan, A. (2017) ecospat: an R package to support spatial analyses and modeling of species niches and distributions. Ecography, 40, 774-787.

Döberl, M. (2010) Alticinae. Catalogue of Palaearctic Coleoptera : Chrysomeloidea (Vol. 6) (ed. by Löbl, I. \& Smetana, A.), pp. 491-563. Apollo Books, Stentrup, Denmark.

Dormann, C.F. (2007) Effects of incorporating spatial autocorrelation into the analysis of species distribution data. Global Ecology and Biogeography, 16, 129-138.

Dormann, C. F., Elith, J., Bacher, S., Buchmann, C., Carl, G., Carré, G., Marquéz, J. R. G., Gruber, B., Lafourcade, B., Leitão, P. J., Münkemüller, T., McClean, C., Osborne, P. E., Reineking, B., Schröder, B., Skidmore, A. K., Zurell, D. \& Lautenbach, S. (2013) Collinearity: a review of methods to deal with it and a simulation study evaluating their performance. Ecography, 36, 27-46.

Dullinger, S., Gattringer, A., Thuiller, W., Moser, D., Zimmermann, N. E., Guisan, A., Willner, W., Plutzar, C., Leitner, M. \& Mang, T. (2012) Extinction debt of high-mountain plants under twenty-first-century climate change. Nature Climate Change, 2, 619.

ESRI 2011. ArcGIS Desktop: Release 10. Redlands, CA: Environmental Systems Research Institute.

Fielding, A. H. \& Bell, J. F. (1997) A review of methods for the assessment of prediction errors in conservation presence/absence models. Environmental Conservation, 24, 38-49.

Forrest, J. L., Wikramanayake, E., Shrestha, R., Areendran, G., Gyeltshen, K., Maheshwari, A., Mazumdar, S., Naidoo, R., Thapa, G. J. \& Thapa, K. (2012) Conservation and climate change: Assessing the vulnerability of snow leopard habitat to treeline shift in the Himalaya. Biological Conservation, 150, 129-135. 
Franklin, J. (2013) Species distribution models in conservation biogeography: developments and challenges. Diversity and Distributions, 19, 1217-1223.

Gherghel, I., Brischoux, F. \& Papeş, M. (2018) Using biotic interactions in broad-scale estimates of species' distributions. Journal of Biogeography, 45, 2216-2225.

Guisan, A., Lehmann, A., Ferrier, S., Austin, M., Overton, J. M. C., Aspinall, R., \& Hastie, T. (2006) Making better biogeographical predictions of species' distributions. Journal of Applied Ecology, 43, 386-392.

Guisan, A., Thuiller, W. \& Zimmermann, N. E. (2017) Habitat Suitability and Distribution Models: With Applications in R. Cambridge University Press, Cambridge, UK.

Hijmans, R. J., Cameron, S. E., Parra, J. L., Jones, P. G. \& Jarvis, A. (2005) Very high resolution interpolated climate surfaces for global land areas. International journal of climatology, 25, 1965-1978.

Hijmans, R. J. (2015) raster: Geographic Data Analysis and Modeling. R package version 2.8-19

Hof, A. R., Jansson, R. \& Nilsson, C. (2012) How biotic interactions may alter future predictions of species distributions: future threats to the persistence of the arctic fox in Fennoscandia. Diversity and Distributions, 18, 554-562.

Howard, C., Stephens, P. A., Pearce-Higgins, J. W., Gregory, R. D., \& Willis, S. G. (2014) Improving species distribution models: the value of data on abundance. Methods in Ecology and Evolution, 5, 506-513.

Iannella, M., Cerasoli, F. \& Biondi, M. (2017) Unraveling climate influences on the distribution of the parapatric newts Lissotriton vulgaris meridionalis and L. italicus. Frontiers in Zoology, 14, 55.

Iannella, M., Cerasoli, F., D’Alessandro, P., Console, G., \& Biondi, M. (2018) Coupling GIS spatial analysis and Ensemble Niche Modelling to investigate climate change-related threats to the Sicilian pond turtle Emys trinacris, an endangered species from the Mediterranean. PeerJ, 6, e4969.

Inouye, D. W. (2008) Effects of climate change on phenology, frost damage, and floral abundance of montane wildflowers. Ecology, 89, 353-62.

Jolivet, P. \& Verma, K. K. (2002) Biology of leaf beetles. Intercept Itd, Andover, U.K., 322 pp.

Kassambara, A. \& Mundt, F. (2017) factoextra: extract and visualize the results of multivariate data analyses. R package version 1.0.4 
644 Konstantinov, A. S. (1991) On taxonomy of Asiorestia (Coleoptera, Chrysomelidae, Alticinae). [In Russian]. Zoologicheskii Zhurnal, 70, 143-144.

646

647

Konstantinov, A. S. \& Vandenberg, N. J. (1996) Handbook of Palearctic flea beetles (Coleoptera Chrysomelidae Alticinae). Contributions on Entomology, International, 1, 237-436.

Lamprecht, A., Semenchuk, P. R., Steinbauer, K., Winkler, M., \& Pauli, H. (2018) Climate change leads to accelerated transformation of high-elevation vegetation in the central Alps. New Phytologist, doi: $10.1111 /$ nph. 15290

Li, J., McCarthy, T. M., Wang, H., Weckworth, B. V., Schaller, G. B., Mishra, C., Lu, Z. \& Beissinger, S.R. (2016) Climate refugia of snow leopards in High Asia. Biological Conservation, 203, 188-196.

Liu, C. R., White, M. \& Newell, G. (2013) Selecting thresholds for the prediction of species occurrence with presence-only data. Journal of Biogeography, 40, 778-789.

Marmion, M., Parviainen, M., Luoto, M., Heikkinen, R. K., \& Thuiller, W. (2009) Evaluation of consensus methods in predictive species distribution modelling. Diversity and distributions, 15, 59-69.

McCormack, J. E., Zellmer, A. J., \& Knowles, L. L. (2010) Does niche divergence accompany allopatric divergence in Aphelocoma jays as predicted under ecological speciation?: insights from tests with niche models. Evolution: International Journal of Organic Evolution, 64, 1231-1244.

Meinshausen, M., Smith, S. J., Calvin, K., Daniel, J. S., Kainuma, M. L.T., Lamarque, J. F., Matsumoto, K., Montzka, S. A., Raper, S. C.B., Riahi, K., Thomson, A., Velders, G. J. M. \& van Vuuren, D. P. P. (2011) The RCP greenhouse gas concentrations and their extensions from 1765 to 2300. Climatic Change, 109, 213-241.

Murray, K. A., Rosauer, D., McCallum, H., \& Skerratt, L. F. (2010) Integrating species traits with extrinsic threats: closing the gap between predicting and preventing species declines. Proceedings of the Royal Society of London B: Biological Sciences, doi:10.1098/rspb.2010.1872.

Nadein, K. S. \& Beždek, J. (2014) Galerucinae Latreille 1802. Handbook of Zoology, Volume 4/40: Coleoptera, Beetles, Volume 3: Morphology and Systematics (Phytophaga) (ed. by Leschen, R.A.B. \& Beutel, R.G.), pp. 251-259. Walter de Gruyter Publishers, Berlin, Deutschland. 
Naimi, B. (2015) usdm: Uncertainty analysis for species distribution models. R package version 1.1-12.

Pateiro-López, B. \& Rodrıguez-Casal, A. (2010) Generalizing the convex hull of a sample: the R package alphahull. Journal of Statistical software, 34, 1-28.

PESI (2018) Pan-European Species directories Infrastructure. Accessed through www.eu-nomen.eu/portal, at 2018-03-31.

Peterson, A. T. \& Soberon, J. (2012) Species Distribution Modeling and Ecological Niche Modeling: Getting the Concepts Right. Natureza \& Conservação, 10, 1-6.

Peterson, A. T., Cobos, M. E., \& Jiménez-García, D. (2018) Major challenges for correlational ecological niche model projections to future climate conditions. Annals of the New York Academy of Sciences, $1429,66-77$.

Phillips, S. J., Anderson, R. P. \& Schapire, R. E. (2006) Maximum entropy modeling of species geographic distributions. Ecological Modelling, 190, 231-259.

Pyron, R. A. \& Burbrink, F. T. (2009) Lineage diversification in a widespread species: roles for niche divergence and conservatism in the common kingsnake, Lampropeltis getula. Molecular Ecology, $18,3443-3457$.

R Core Team (2018) R: A language and environment for statistical computing. R Foundation for Statistical Computing, Vienna, Austria. URL https://www.R-project.org/.

Reino, L., Ferreira, M., Martínez-Solano, Í., Segurado, P., Xu, C. \& Márcia Barbosa, A. (2017) Favourable areas for co-occurrence of parapatric species: niche conservatism and niche divergence in Iberian tree frogs and midwife toads. Journal of Biogeography, 44, 88-98.

Rogora, M., Frate, L., Carranza, M. L., Freppaz, M., Stanisci, A., Bertani, I., Bottarin, R., Brambilla, A., Canullo, R., Carbognani, M., Cerrato, C., Chelli, S., Cremonese, E., Cutini, M., Di Musciano, M., Erschbamer, B., Godone, D., locchi, M., Isabellon, M., Magnani, A., Mazzola, L., Morra di Cella, U., Pauli, H., Petey, M., Petriccione, B., Porro, F., Psenner, R., Rossetti, G., Scotti, A., Sommaruga, R., Tappeiner, U., Theurillat, J. P., Tomaselli, M., Viglietti, D., Viterbi, R., Vittoz, P., Winkler, M. \& 
Matteucci, G. (2018) Assessment of climate change effects on mountain ecosystems through a cross-site analysis in the Alps and Apennines. Science of the total environment, 624, 1429-1442.

Schoener, T. W. (1970) Nonsynchronous spatial overlap of lizards in patchy habitats. Ecology, 51, 408-418.

Silva, D. P., Dew, R. M., Vilela, B., Stevens, M. I., \& Schwarz, M. P. (2018). No deaths in the desert: predicted responses of an arid-adapted bee and its two nesting trees suggest resilience in the face of warming climates. Insect Conservation and Diversity, 11, 449-463.

Sofaer, H. R., Jarnevich, C. S., \& Flather, C. H. (2018) Misleading prioritizations from modelling range shifts under climate change. Global Ecology and Biogeography, 27, 658-666.

Strandberg, G., Bärring, L., Hansson, U., Jansson, C., Jones, C., Kjellström, E., Kolax, M., Kupiainen, M., Nikulin, G., Samuelsson, P., Ullerstig, A. \& Wang, S. (2014) CORDEX scenarios for Europe from the Rossby Centre regional climate model RCA4. SMHI.

Thuiller, W., Lavorel, S., Araujo, M. B., Sykes, M. T. \& Prentice, I. C. (2005) Climate change threats to plant diversity in Europe. Proceedings of the National Academy of Sciences, 102, 8245-8250.

Thuiller, W., Lafourcade, B., Engler, R. \& Araujo, M. B. (2009) BIOMOD - a platform for ensemble forecasting of species distributions. Ecography, 32, 369-373.

Thuiller, W., Georges, D., Engler, R., Breiner, F., Georges, M. D. (2016) biomod2: Ensemble platform for species distribution modeling. R package version 3.3-7.

Thuiller, W., Guéguen, M., Bison, M., Duparc, A., Garel, M., Loison, A., Renaud, J., Poggiato, G. \& Wiersma, Y. (2018) Combining point-process and landscape vegetation models to predict large herbivore distributions in space and time-A case study of Rupicapra rupicapra. Diversity and Distributions, 24, $352-362$.

Urbani, F., D’Alessandro, P., Frasca, R., \& Biondi, M. (2015) Maximum entropy modeling of geographic distributions of the flea beetle species endemic in Italy (Coleoptera: Chrysomelidae: Galerucinae: Alticini). Zoologischer Anzeiger-A Journal of Comparative Zoology, 258, 99-109. 
Urbani, F., D'Alessandro, P., \& Biondi, M. (2017) Using maximum entropy modeling (MaxEnt) to predict future trends in the distribution of high altitude endemic insects in response to climate change. Bulletin of Insectology, 70, 189-200.

Van der Putten, W. H., Macel, M., \& Visser, M. E. (2010) Predicting species distribution and abundance responses to climate change: why it is essential to include biotic interactions across trophic levels. Philosophical Transactions of the Royal Society of London B: Biological Sciences, 365, 2025-2034.

VanDerWal, J., Shoo, L. P., Graham, C. \& Williams, S. E. (2009) Selecting pseudo-absence data for presenceonly distribution modeling: How far should you stray from what you know? Ecological Modelling, 220, 589-594.

Warren, D. L., Glor, R. E. \& Turelli, M. (2008) Environmental niche equivalency versus conservatism: quantitative approaches to niche evolution. Evolution, 62, 2868-2883.

Zhang, J., Nielsen, S. E., Chen, Y., Georges, D., Qin, Y., Wang, S. S., Svenning, J.C. \& Thuiller, W. (2017) Extinction risk of North American seed plants elevated by climate and land-use change. Journal of Applied Ecology, 54, 303-312. 


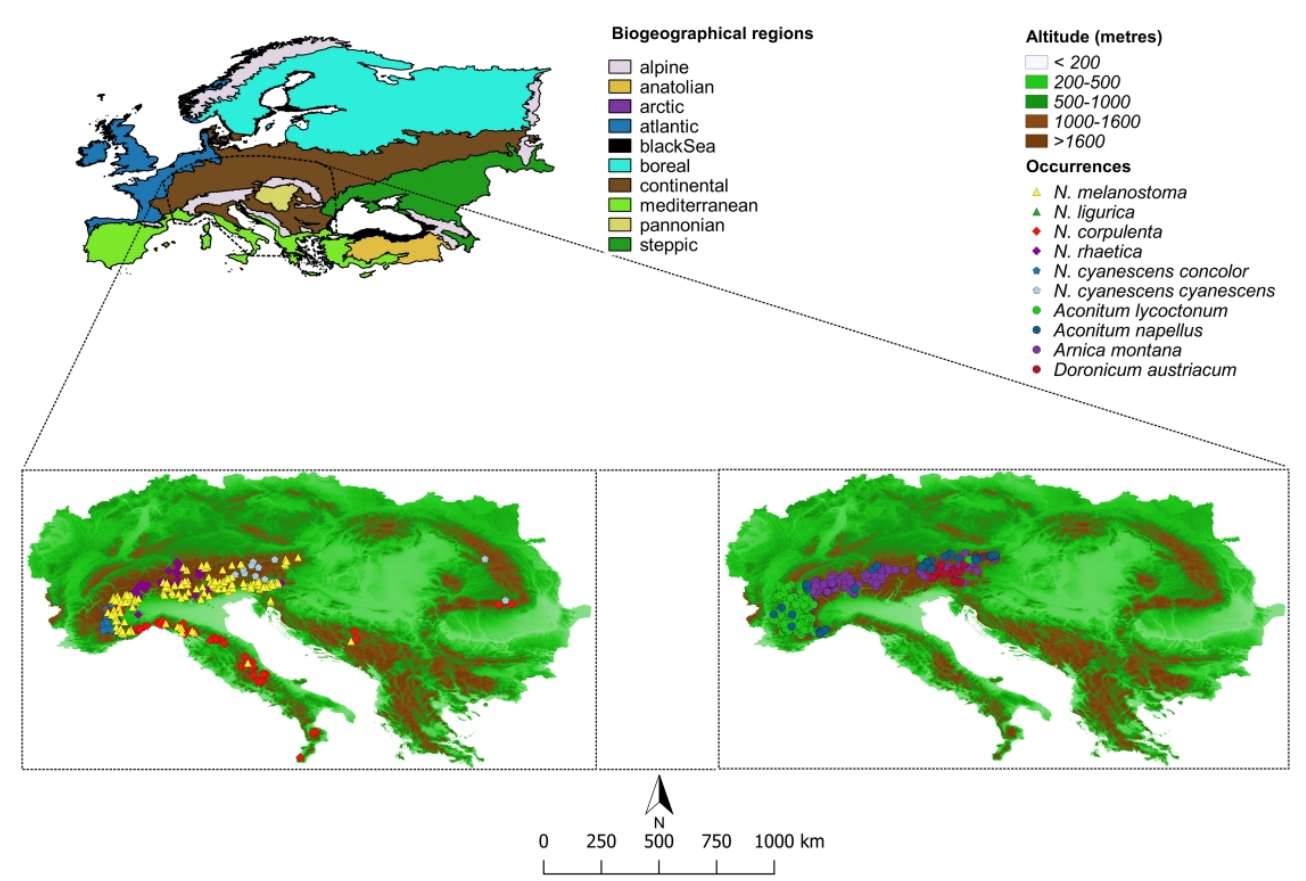

Figure 1. European biogeographical regions, as defined by the European Environmental Agency (EEA), with a zoom on the study area, showing the altitudinal zonation and the occurrences for the six target Neocrepidodera taxa and the candidate host plants.

$222 \times 150 \mathrm{~mm}(600 \times 600 \mathrm{DPI})$ 
(a)

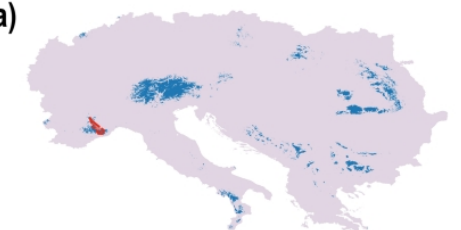

(c)

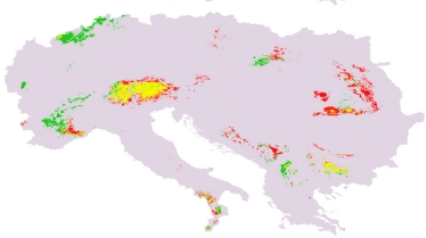

(e)

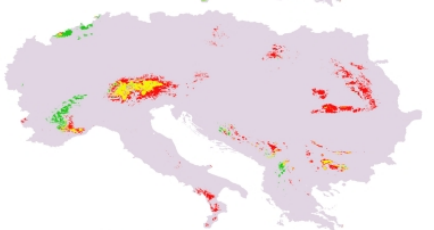

(g)

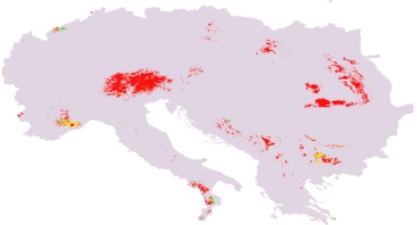

(b)

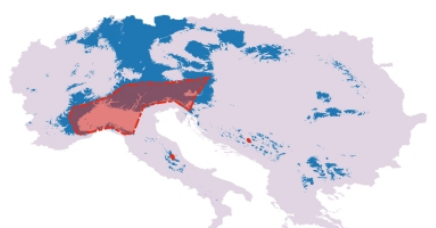

(d)

E-ji-j Current range Binarized Habitat Suitability

Unsuitable

- Suitable

Suitability Shifts

Loss

Stable

Gain

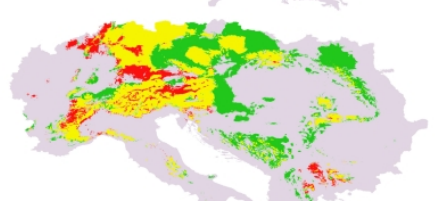

(f)

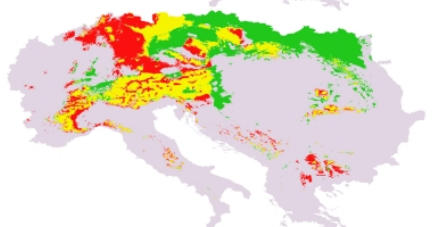

(h)

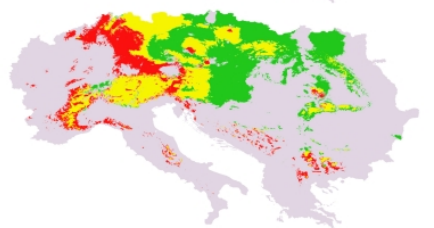

Figure 2. Suitable areas under the current scenario, obtained from the predictions of the weighted mean Ensemble Model, and a-hull-based current range (hatched polygons) for (a) N. ligurica and (b) $\mathrm{N}$. melanostoma; predicted shifts in habitat suitability by 2070 under RCPs $2.6,4.5$ and 8.5 for (c), (e) and (g) N. ligurica, and (d), (f) and (h) N. melanostoma, respectively. 
(a)

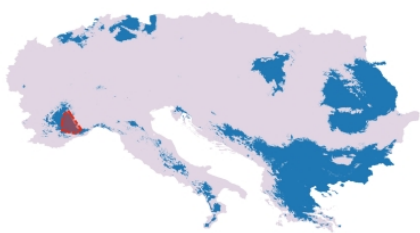

(c)

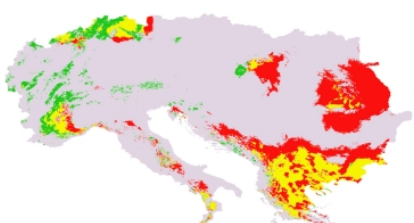

(e)

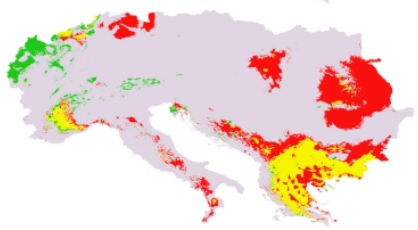

(g)

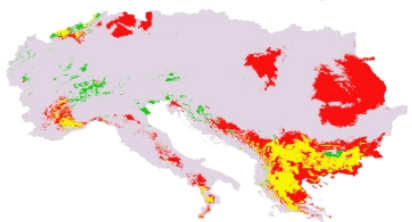

(b)

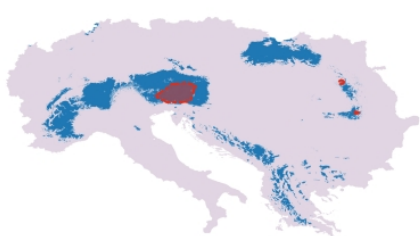

(d)

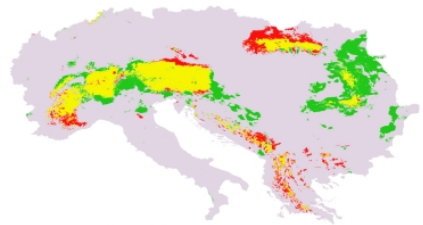

(f)

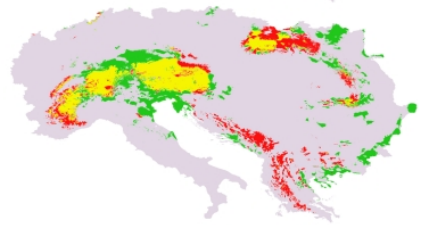

(h)

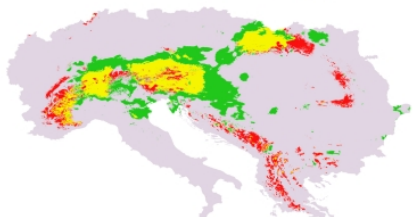

Figure 3. Suitable areas under the current scenario, obtained from the predictions of the weighted mean Ensemble Model, and a-hull-based current range (hatched polygons) for (a) N. cyanescens concolor and (b) N. cyanescens cyanescens; predicted shifts in habitat suitability by 2070 under RCPs $2.6,4.5$ and 8.5 for (c), (e) and (g) N. cyanescens concolor, and (d), (f) and (h) N. cyanescens cyanescens, respectively. 
(a)

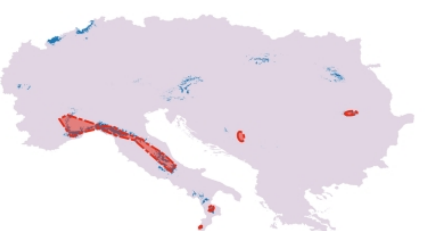

(c)

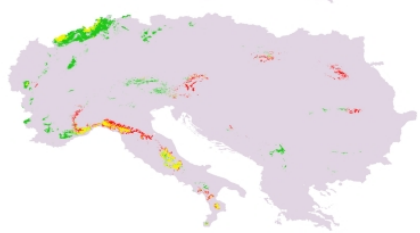

(e)

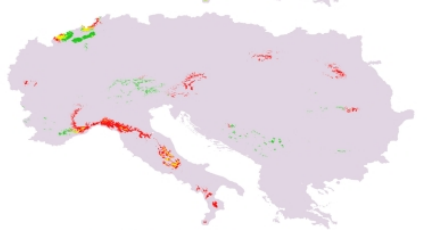

(g)

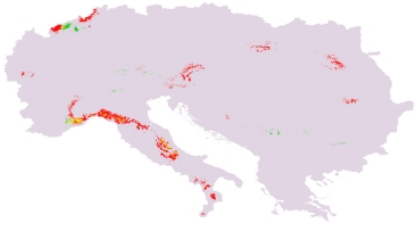

(b)

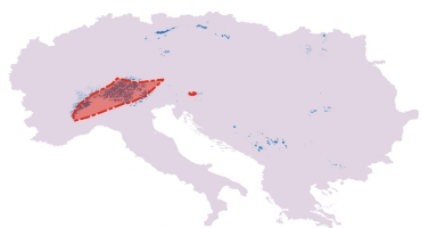

(d)

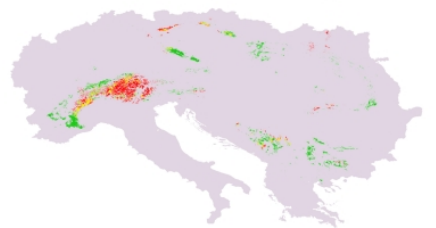

(f)

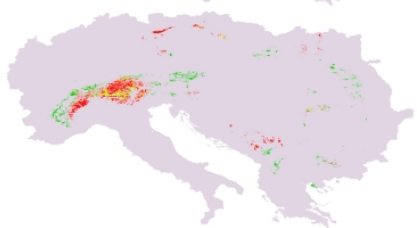

(h)

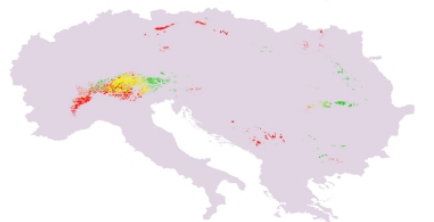

Figure 4. Suitable areas under the current scenario, obtained from the predictions of the weighted mean Ensemble Model, and a-hull-based current range (hatched polygons) for (a) $N$. corpulenta and (b) $N$. rhaetica; predicted shifts in habitat suitability by 2070 under RCPs $2.6,4.5$ and 8.5 for (c), (e) and (g) $N$. corpulenta, and (d), (f) and (h) N. rhaetica, respectively. 

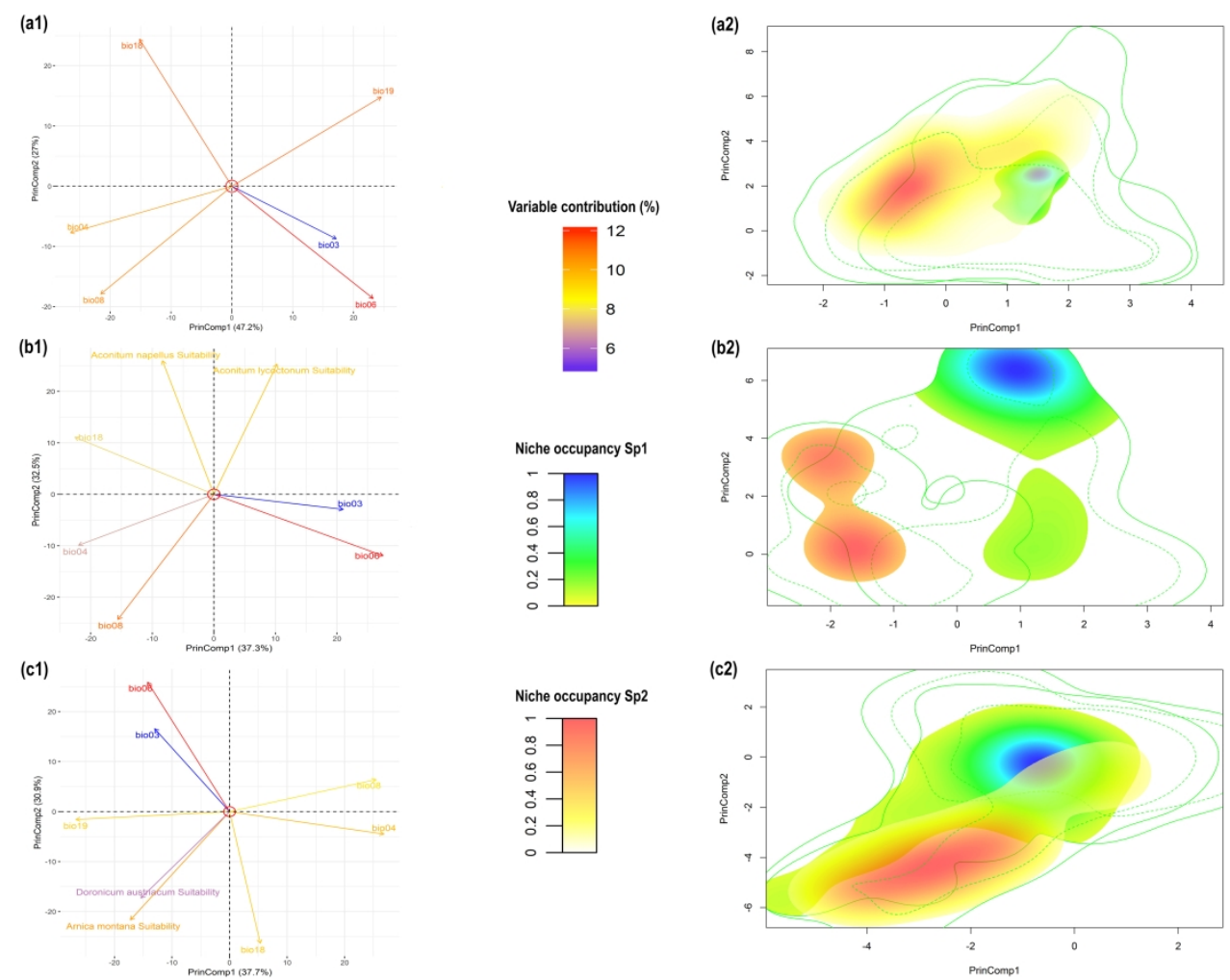

Figure 5. Contributions of the input predictors along the first two principal components ('PCA-env', Broennimann et al., 2012) for: (a1) N. ligurica and N. melanostoma; (b1) N. cyanescens concolor and $N$. cyanescens cyanescens; (c1) N. corpulenta and N. rhaetica. Density of occurrence in the environmental space defined by the principal components for: (a2) N. ligurica (Sp1) and N. melanostoma (Sp2); (b2) N. cyanescens concolor (Sp1) and N. cyanescens cyanescens (Sp2); (c2) N. corpulenta (Sp1) and N. rhaetica (Sp2). Within the density plots, solid contour lines represent the full environmental background and dashed contour lines represent $50 \%$ of the background environment. 
(a)

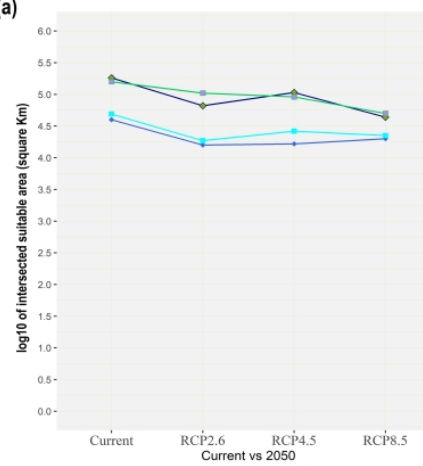

(b)

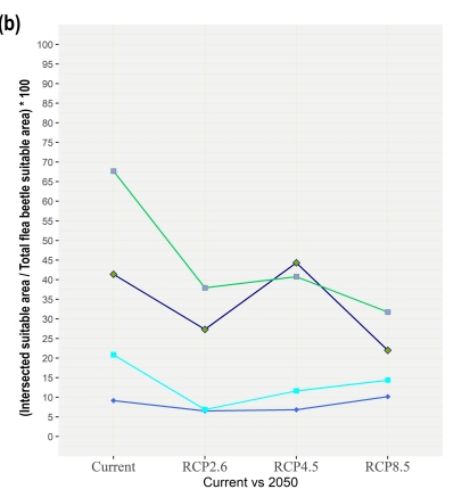

(c)

Neost plant $\rightarrow N$. cyanescens concolor $X$ Aconitum lycoctonum - N. cyanescens cyanescens X Aconitum lyococtonum $-N$. cyanescens cyanescens $X$ Aconitum napellus (d)

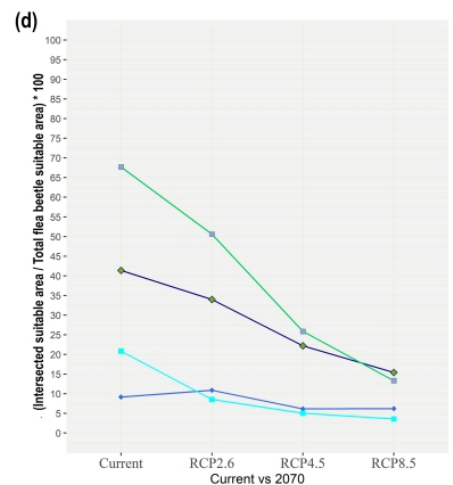

Figure 6. Variation in the extent of overlapping suitable area between the two $N$. cyanescens subspecies and the corresponding candidate host plants (Aconitum lycoctonum and $A$. napellus) from the current scenario to 2050 (a) and 2070 (c) under the three RCPs; variation in the percent extent of overlapping suitable area with respect to the overall suitable area for the flea beetle under the different RCPs in 2050 (b) and 2070 (d).

$457 \times 349 \mathrm{~mm}(300 \times 300 \mathrm{DPI})$ 

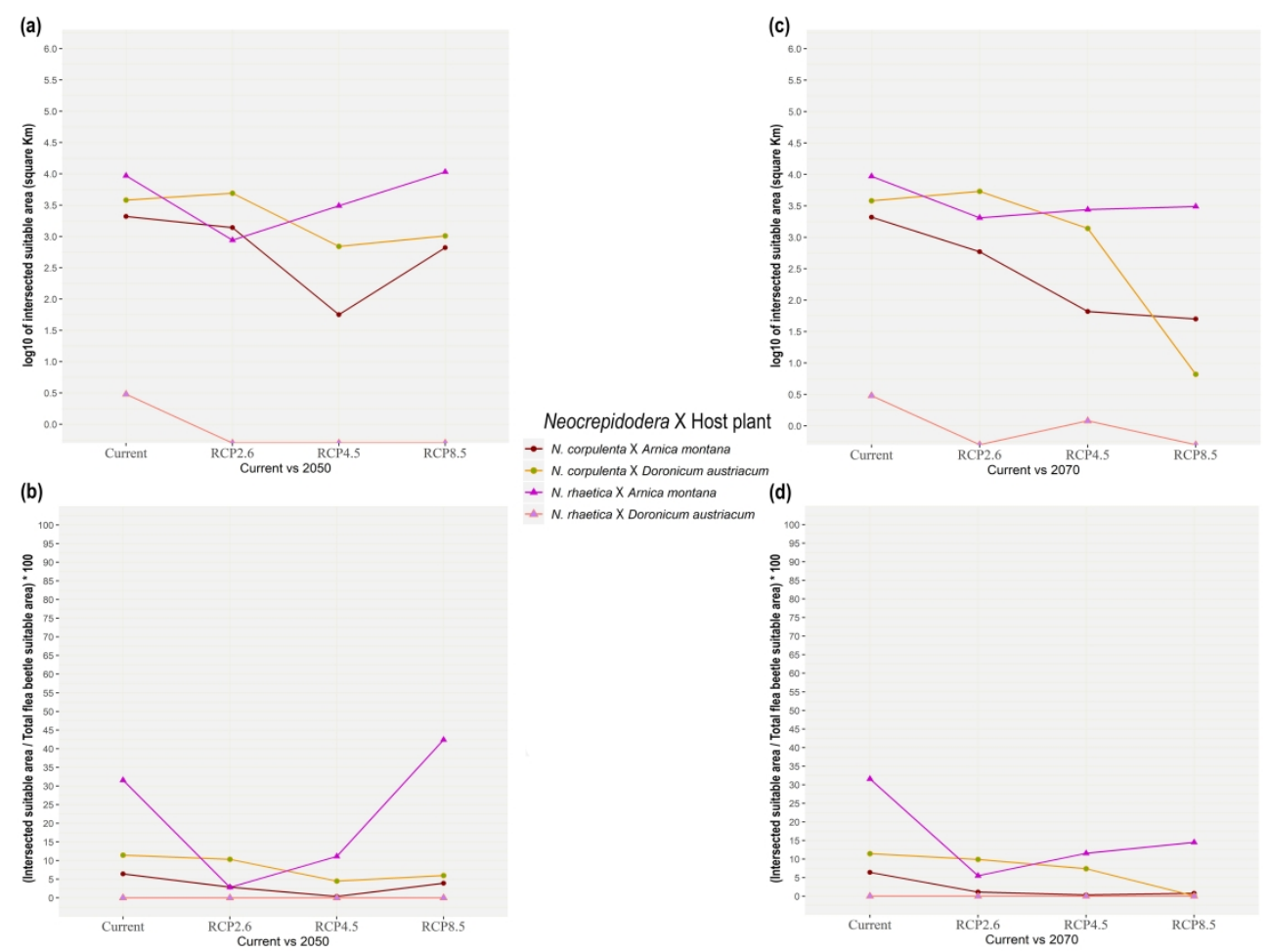

Figure 7. Variation in the extent of overlapping suitable area between $N$. corpulenta, $N$. rhaetica and the corresponding candidate host plants (Arnica montana and Doronicum austriacum) from the current scenario to 2050 (a) and 2070 (c) under the three RCPs; variation in the percent extent of overlapping suitable area with respect to the overall suitable area for the flea beetle under the different RCPs in 2050 (b) and 2070 (d).

$457 \times 349 m m(300 \times 300$ DPI) 